\title{
An assessment of the prescribing skills among second year MBBS students in a tertiary care teaching hospital
}

\author{
Abdul Samath Suhaina, Selvakumar Suseela Supriya*
}

Department of Pharmacology, Sree Mookambika Institute of Medical Sciences, Kulasekharam, Tamil Nadu, India

Received: 17 November 2020

Accepted: 16 December 2020

\section{*Correspondence:}

Dr. Selvakumar Suseela Supriya,

Email: sssupriya621@gmail.com

Copyright: () the author(s), publisher and licensee Medip Academy. This is an open-access article distributed under the terms of the Creative Commons Attribution Non-Commercial License, which permits unrestricted non-commercial use, distribution, and reproduction in any medium, provided the original work is properly cited.

\begin{abstract}
Background: The medical undergraduate curriculum includes training in prescription writing from second year under Pharmacology. This study assesses the prescription writing skills of second year MBBS students in Sree Mookambika institute of medical sciences. The study can promote awareness among the medical students about the rational application of drug prescribing skills.

Methods: After ethical clearance from the Institutional research committee, the cross-sectional study was conducted among 115, second year MBBS students who were above 18 years of age. Parameters like patient and doctor information, drug information and legibility of the prescription was assessed.

Results: Of the 115 students who participated in the study, only $86(74.7 \%)$ students got a score $4 / 4$ for patient-related information and no student got 5/5 with respect to doctor related information. 98 students (85.2\%) got 6/6 with regards to drug information. The most lacking information was the qualification of the doctor, followed by the total quantity of the drug prescribed. The legibility of the prescriptions was also not up to the mark with only 22 students (19.1\%) who got a $4 / 4$.

Conclusions: The prescription writing skills among second year undergraduate students are suboptimal. Periodic assessment of the students must be done to evaluate their knowledge on prescription writing and the training clinicians must help to fill the knowledge-practice gap. WHO recommended six step prescription writing model must be followed and emphasized among students.
\end{abstract}

Keywords: Prescription writing, Medical errors, Medical curriculum, Undergraduate training

\section{INTRODUCTION}

Prescribing drug is generally done by qualified doctors and trained medical professionals. Even though undergraduate students of health care are not allowed to prescribe drugs, they are trained to prescribe drugs under the supervision of a clinical teacher. ${ }^{1}$ Training the medical undergraduate students to prescribe helps them in obtaining a strong knowledge about the drug action and therapeutic principles to give quality health in the future developments of the health care system. ${ }^{2}$

Rational drug prescribing means to prescribe appropriate drug in adequate dose for sufficient duration at a reasonable cost to obtain the best possible effect. ${ }^{3}$ Training and assessing the knowledge of medical undergraduate students should be done on a regular basis in order to promote rational drug prescription. ${ }^{4}$

Prescription writing is an important skill which depends on the knowledge of drugs, pharmacodynamics, its benefits and adverse effects. ${ }^{5}$ In India, problem based learning is the current teaching methodology in various medical colleges. Second year MBBS students have pharmacology course which helps the students to think critically in order to provide appropriate prescription for the patient. ${ }^{6}$ This study can promote an awareness among medical students about the correct and rational application of drug 
prescribing skills which can minimize prescribing errors and also lead to an excellent future healthcare delivery system.

\section{Aim and objectives}

Aim of the current study was to assess the prescription writing skill of preclinical undergraduate medical students. Objectives of the study were to assess the knowledge of prescribing drugs and to assess the proper prescription writing skills following the WHO six-step model of rational prescribing.

\section{METHODS}

A cross sectional study was conducted in the department of pharmacology of Sree Mookambika institute of medical sciences, Kulashekaram, Kanyakumari district, Tamilnadu, among second year MBBS students for a period of one month. Convenient sampling of groups was done and all second year MBBS students were included in the study. First year, third year, pre-final and final year students, and students under 18 years of age or not willing to participate in the study were excluded. No placebo or medical devices were used. Permission was obtained from the director of the institution and head of the department of Pharmacology for doing the study. The study was initiated after ethical clearance from the institutional research committee (IRC) and the institutional human ethics committee (IHEC). The study methods were clearly explained to the participating students before the filled prescription was obtained.

The following parameters were studied; patient identification (maximum score 4-1 each for patient name, age, gender and date of prescription), doctor's identification (maximum score 5-1 each for doctor's name, qualification, registration number, full address, and doctors signature), drug information (maximum score 7-1 each for treatment, form, name of medicine, strength, dosage instructions, duration, and total quantity) and. legibility of prescription, as assessed by a single investigator using an index and was graded on 4-point scale; score 1: more than one aspect not clear, score 2: one aspect not clear (patient name/drug name), score 3: clear but requires effort to read and score 4: prescription details are clear and legible. Data were collected using proforma and converted to MS Excel for analysis. Data were presented as frequency and percentage.

\section{RESULTS}

Out of the 115 students who participated in the study, all the students had mentioned the patient name and date of prescription. 110 students $(95.6 \%)$ paid attention to writing the patient's age on the prescription and 86 students $(74.7 \%)$ wrote the patient's gender (Figure 1). Information about the name of medicine was found in 113 prescriptions (98\%) and only $46.9 \%$ of the students mentioned about the total quantity of the medicines to be used. The form of the drug and duration of usage was addressed in $85.2 \%$ of the prescriptions. The diagnosis and treatment for which the medicine is prescribed was seen in 109 prescriptions. Based on these, the patient identification scoring was calculated as pictured by (Figure 2). The deficient element in patient identification was the gender of the patient followed by age.

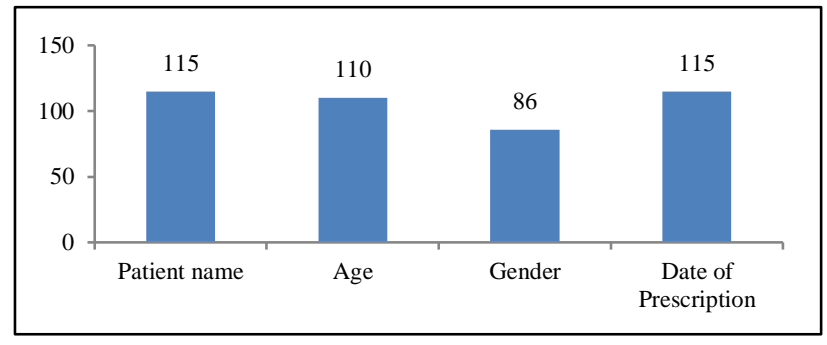

Figure 1: Patient identifiers.

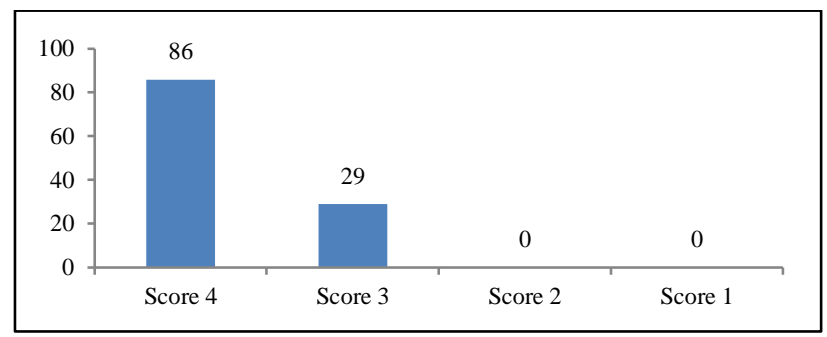

Figure 2: Patient identification score.

With regards to doctor information, the performance score for doctor's name, registration number and doctor signature was $115.60 \%$ of the prescription had information about the doctor's full address and only $1.7 \%$ of the prescription had information about the doctor's qualification. Qualification of the doctor was the most deficient element under doctor information (Figure 3-4).

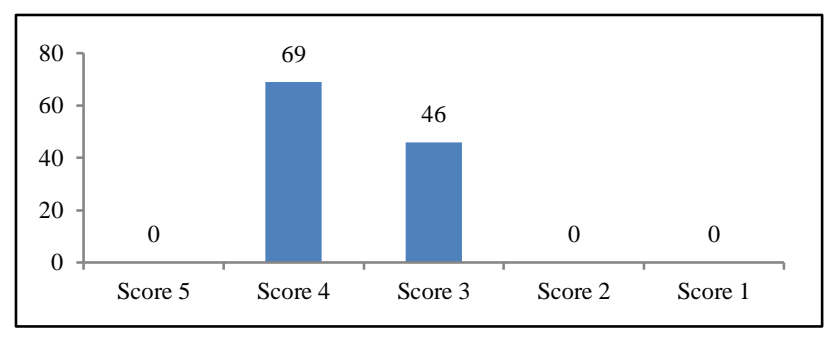

Figure 1: Doctors identification score.

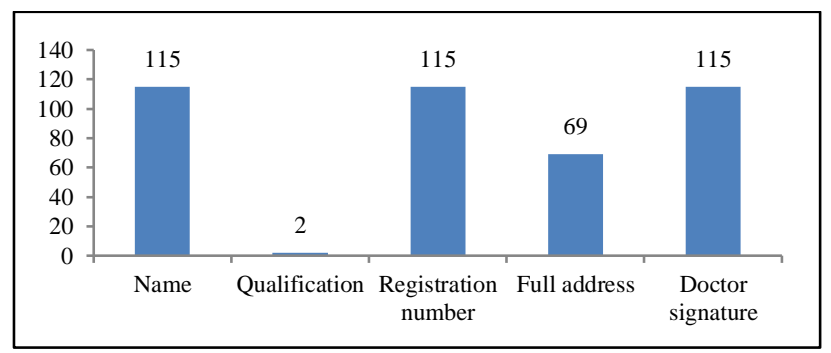

Figure 2: Doctors identification. 
Among the drug information components, the score ranged highest in the name of the medicine (113) and dosage instruction (110), while the least scoring was to the total quantity of the drug (54). Information on form and duration of the time the medicine is to be taken was seen in $85.2 \%$ of the prescriptions and about $94.7 \%$ of the prescriptions had mentioned about the treatment plan for which the drug is prescribed. The scoring related to the strength of the prescribed medicine was 108 (Figure 5-6).

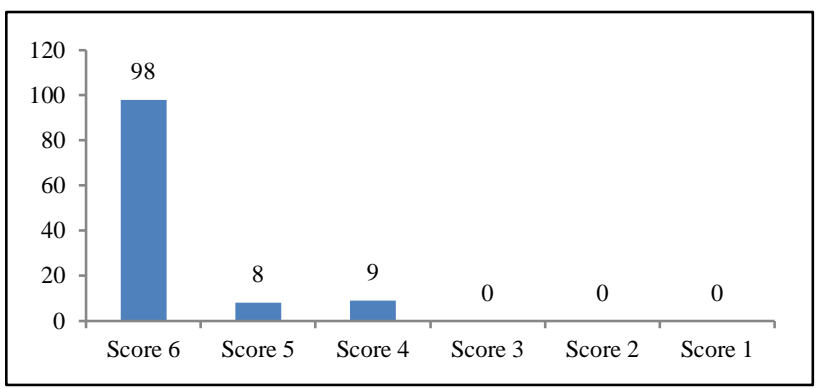

Figure 3: Drug information score.

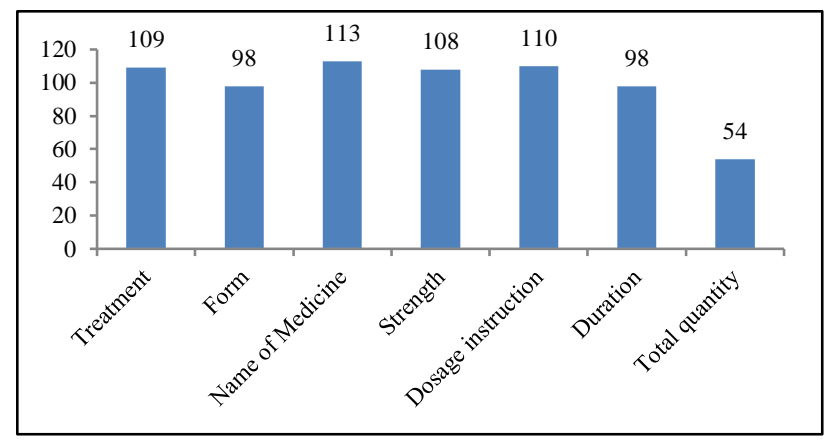

Figure 4: Drug information.

The legibility of the prescriptions as calculated by a single investigator had the highest score of 4 in $19.1 \%$ (22) of the prescriptions and the least score of 1 in $3.4 \%$ (4) of the prescriptions. A score 3 was obtained by most prescriptions $75.6 \%$ (87) and a score 2 in $1.73 \%$ (2) prescriptions.

\section{DISCUSSION}

Prescription writing is one of the core competencies that need to be developed by a medical graduate, following prompt diagnosis. The term 'prescribe' originates from the Latin word praescriptio (n-) which means 'pre' (before) and 'script' (writing or written), that refers to the fact that the prescription must be written before the ordering the use of a drug or remedy. ${ }^{7}$ Proper transcribing is an essential skill of an exemplary prescription. Apart from carrying details about the name of the drugs and their dosage, a prescription is also a valid legal document to patients, pharmacists and doctors in the event of an adverse drug reaction. Therefore, proper documentation of the patient's name and address and also the doctor's information is mandatory. ${ }^{8}$ Even a small mistake in a prescription can lead to serious medical errors and can take a heavy toll in medical and health sector. Prescription errors are the $8^{\text {th }}$ leading cause of death in the United States and globally, $1 \%$ of the total health expenditure is due to a wrong prescription. Prescription errors also rank $3^{\text {rd }}$ among the common medical errors, the first and second being wrong diagnosis and delayed diagnosis respectively., ${ }^{9,10}$

The results of this study reveal that second year MBBS students made more mistakes were noted in the doctor and drug related information. The most deficient element was the doctor's qualification (1.7\%) followed by the total quantity of the drug $(46.9 \%)$. Although prescription writing is included in the second year undergraduate pharmacology teaching curriculum, students did not seem to perform well in this study. This indicates that either the theory based teaching is insufficient or the students did not pay due importance to this topic. A lack of revision and appropriate practice may be other reasons. The students also lacked legibility in prescription writing. Only $19.1 \%$ of the students obtained a maximum legibility score of 4 and about $75.6 \%$ of the prescriptions were clear but required more effort to read.

An improvement in the training should be made as per WHO recommendations that include patient and doctor identity, generic name of the drug, dosage, frequency and duration of use of the medicament. ${ }^{11}$ Prescribing errors can have an adverse effect on the treatment outcome and therefore, prescribing competency should be developed early through proper education and interventional aids. The results of this study are similar to that of the previous studies done so far in India. A study conducted by Sudha among $1^{\text {st }}$ year and $2^{\text {nd }}$ year MBBS students showed that the students lacked prescribing competence and that they needed additional training and practice. ${ }^{12}$ Additionally, the results of the present study also showed that most prescriptions lacked legibility. A study in Texas by Winslow et al among 3 patient care units showed that an illegible handwriting can land in serious medical errors and adverse drug events. ${ }^{13,14}$ A detailed explanatory curriculum with more emphasis on clear and legible prescription writing must be developed and taught to the students right from second year.

Many participants of the study failed to mention their qualification on the prescription, which can amount to negligence on the doctor's side. Mentioning the registration number is also important in countries like India, to avoid any legal issues in the case of an adverse event. All study participants had mentioned the registration number in this study. Many students also failed to mention the gender of the patient in this study. This is not light because a significant disparity exists between men and women in drug dosing and the intensity of drug usage. A lack of information about the total quantity of drug to be used and the form and duration for which it is to be taken was seen in most prescriptions. These results are similar to the study results of Kumar et al who conducted study among $1^{\text {st }}$ and $2^{\text {nd }}$ year MBBS students in May-June 2010 in Nepal. ${ }^{15}$ This element is 
important to ensure the success and compliance of any recommended therapy.

Overall this study concludes that the prescription writing skills among second year MBBS students are suboptimal and they should focus on certain elements during the clinical years. Prescription writing involves a mixture of skills, knowledge and judgment and the undergraduate medical curriculum includes this training phase under pharmacology. A guide to good prescribing should be included in the curriculum to throw more light onto this area. An improperly filled prescription can compromise the patient safety and also lead to irreversible serious damage to the patient health. Regular assessment and revision can help the students to reduce prescription errors. The governing bodies of the medical schools can take the necessary measures to develop and introduce a standardized training protocol for the students.

\section{CONCLUSION}

The prescription writing skills among second year MBBS students are suboptimal. Timely evaluation of the undergraduate medical students about their knowledge on prescription writing must be done. WHO recommended prescription writing model must be taught to the students and the errors and adverse effects associated with poor prescription writing must be explained to them. More focus on writing a legible and comprehendible prescription must be made. The knowledge and practice gap must be filled by the training clinicians. All these simple measures can help create a good future doctor community.

\section{Funding: No funding sources}

Conflict of interest: None declared

Ethical approval: The study was approved by the Institutional Ethics Committee

\section{REFERENCES}

1. Akram A, Mohamad N, Salam A, Abdullah D, ZamzamR. Perception of final year dental students on pattern of medication for pulpitis. Dentistry. 2012;159.

2. Maxwell S, Walley T. Teaching safe and effective prescribing in UK medical schools: A core curriculum for tomorrow's doctors. $\mathrm{Br} \mathrm{J}$ Clin Pharmacol. 2003;55:496-503.

3. De vries TPG, Henning RH, Hogerzeil HV, Fresle DA. Guide to good prescribing: a practical manual, World Health Organization, action programme on essential drugs. Available at: https://apps.who. int/iris/handle/10665/590011994. Accessed on 15 October 2020.

4. Jain A, Gupta D, Singh D, Garg Y, Saxena A, Chaudhary $\mathrm{H}$ et al. Knowledge regarding prescription of drugs among dental students - a descriptive study. J Basic Clin Pharma. 2016;7:12-6.

5. Likic R, Maxwell SR. Prevention of medication errors: teaching and training. Br J Clin Pharmacol. 2009;67:656-61.

6. Shahroom NSB, Lakshmi T, Roy A. Knowledge of drug prescription among dental and medical students in India-an online survey. J Adv Pharm Edu Res. 2017;7(2):76-81.

7. Akram A, Mohamad N, Meerah TSM, ZamZam R, Abdullah D. A pilot study-an action research to acquire clinical skill. Procedia Soc Behav Sci. 2012;60:236-40.

8. Dean B, Schachter M, Vincent C, Barber N. Causes of prescribing errors in hospital inpatients: a prospective study. Lancet Lond Engl. 2002;359 (9315):1373-8.

9. Al Khaja KAJ, James H, Sequeira RP. Effectiveness of an educational intervention on prescription writing skill of preclerkship medical students in a problembased learning curriculum. J Clin Pharmacol. 2013;53(5):483-90.

10. Vollebregt JA, Metz JCM, de Haan M, Richir MC, Hugtenburg JG, de Vries TPG. Curriculum development in pharmacotherapy: testing the ability of preclinical medical students to learn therapeutic problem solving in a randomized controlled trial. $\mathrm{Br} \mathrm{J}$ Clin Pharmacol. 2006;61(3):345-51.

11. de Vries TPG, Henning RH, Hogerzeil HV, Fresle DA. Guide to good prescribing - a practical mannual. Available at: http://apps.who.int/medicinedocs/ pdf/whozip23e/who zip23e.pdf. Accessed on 15 October 2020.

12. Sudha MJ, Remya VS. Assessment of prescription writing skills among undergraduate medical students. Int J Basic Clin Pharmacol. 2016;5(4):1586-91.

13. Winslow EH, Nestor VA, Davidoff SK, Thompson PG, Borum JC. Legibility and completeness of physicians' handwritten medication orders. Heart Lung J Crit Care. 1997;26(2):158-64.

14. Boehringer PA, Rylander J, Dizon DT, Peterson MW. Improving the quality of the order-writing process for inpatient orders in a teaching hospital. Qual Manag Health Care. 2007;16(3):215-8.

15. Kumar J, Shaik M, Kathi M, Chetty M, Deka A. Appraisal of prescription writing skills of preclinical undergraduate students in a medical institute of Nepal. J Coll Med Sci. 2012;6(4):7-30.

Cite this article as: Suhaina AS, Supriya SS. An assessment of the prescribing skills among second year MBBS students in a tertiary care teaching hospital. Int J Basic Clin Pharmacol 2021;10:172-5. 